Difficulties in the Approach for Fire Engines Due to Overflowed Parking of a Hospital: Usefulness of Video Analysis for Prevention L. Fdez-Yarritu; M. Ortega; R. De Celis; A. De La Serna; A. Martin; A. Soto; E. Zubeldia; A. Franjo Emergency and Intensive Care Unit, Galdakao Hospital, Spain

Introduction: A badly organized hospital access and parking creates great difficulties to fire engines in case of serious accidents or catastrophes. When planning the preventive actuation in case of a fire in the hospital, it is essential to take into consideration this important handicap.

We present a video analysis to demonstrate this phenomena in our center.

Method: We agreed with the fire brigade to simulate a fire alarm at Galdakao Hospital. During the simulation of extinguishing the fire and rescue, a home video recorded the difficulties concerning access, fire fighting, and evacuation (the hardest ones appeared as a consequence of overflowed parking site).

Conclusions: Difficulties for access of fire engines are particularly serious in a hectic hospital parking area, but they are inevitable. Video analysis is a useful tool for evaluating causes and potential solutions in order to improve actuation plans in case of fire.

Key Words: access; fire-apparatus; hospitals; video analysis

\section{Effects of a Simulated Subway Accident on the Emergency Room of a Hospital}

L. Fdez-Yarritu; E. Barbero; A. De La Serna;

$R$ De Celis; M. Ortega; A. Martin; A. Oleagordia;

J. L. Azpiazu

Galdakao Hospital, Basque Health Service, Spain

Description: This is a videotape of a simulated, underground accident. It was carried out in Bilbao City in the north of Spain. A call to the coordinating center, 0-8-8, mobilized the local police, health professionals, and firefighters. Thirty-five people were evacuated to four different hospitals.

Videotape images of the simulation include: 1) evacuation of the patients from the wagons; 2 ) triage and first health assistance provided on the subway station over the platform; 3) transport through railways to the street and into the ambulances; 4) transport to the hospitals; and 5) the first management at the emergency room.

Objectives: The effects of the drill on the Emergency Room was studied using video analysis. In addition, a survey was carried-out among those doctors who took part in the exercise. The structure and the impact on the demands of the Hospital created by the simulation also are described.

Conclusion: Very positive effects on the training of prehospital services were achieved. This exercise did not comprise a challenge to the staff, since this center meets much bigger demands daily. Ninety-five percent of the surveyed staff disapproved of the trial. The slowness caused by hectic traffic in the Emergency Room and the staging of the exercise at night resulted in annoyance of the staff.

Key Words: hospital; impact of simulation exercise; multi-casualty simulation; simulation; subway

\section{Stress of Nurses in Affected Hospitals at an Earthquake Disaster \\ Akiko Takahashi; Sakayu Terashi; Kiyoji Nagao; \\ Masabiro Irwakiri; Hideto Hirotsune; Taturo Kai; \\ Muneo Obta \\ Osaka University, Osaka, Japan}

Introduction: This surveillance study was performed to identify the stress levels of nurses in affected hospitals after the Hanshin-Awaji Earthquake disaster. The aim of this paper was to study the mental support of nurses in the affected area.

Methods: A questionnaire was completed by 1,931 nurses in six nucleus hospitals in the affected area. The study focused on the relationship between the Impact Event Scale (IES) and the nurses' background at the disaster including personal environment, hospital environment, and physical problems At the same time, the manners with which the nurses coped with the stress of the event was assessed.

Results: A positive correlation between IES and disaster background was found. The fact that the stress levels of the affected nurses was dealt with in several ways and in a delayed fashion was uncovered. The hospital environment with human relationships, relief from outside, and provision of materials, promoted more stress as opposed to the on-site environment.

Conclusion: These result suggest that coping skills are important factors in dealing with nurses' stress. Additionally, basic knowledge and skills on disaster nursing will bring less stress to nurses in disaster situation.

Key Words: disaster; Impact Event Scale (IES); nursing; stress

\section{Session 4A: Training \\ Chairpersons: \\ S. Lennquist (Sweden) \\ M. Fahey (New Zealand)}

\section{Quality of EMTs' Vocational Training:}

Results of an Empirical Investigation in Germany

Klaus Runggaldier

University of Osnabruck, Osnabruck, Germany

The qualification of EMTs is one of the components for success in EMS. A high qualification is based on a good vocational training. Opinions in Germany about the quality of the qualification of EMTs vary considerably. Some believe the qualification of the EMTs is sufficient. However, most experts believe that the qualifications of the EMTs is inadequate. Both groups agree that their findings are not based on facts, but upon personal experiences and opinions. 
During the last three years, an interdisciplinary research group at the University of Osnabruck collected empirical data about the quality of vocational training of EMTs in Germany. This investigation used a special, standardized "Emergency-Parcours" at vocational training schools in Germany. This "Emergency-Parcours" included: 1) stations of IV access; 2) intubation; 3) electrocardiogram interpretation; 4) splinting a fracture; 5) helmet-removal with immobilization of the cervical spine; and 6) extended cardio-pulmonary resuscitation (BCLS and ACLS). The trainees, who were tested in this "Emergency-Parcours" were videotaped by a professional film team. The film documents were made in order to analyze and evaluate the study in an objective and standardized way.

Some of the results were surprising:

1) The quality of the vocational training of EMS in Germany varied considerably among schools since it is not standardized. The study showed that the qualification of EMTs after finishing their vocational training, is not similar. Patients with the same symptoms are not necessarily treated in the same way by EMTs; and

2) Most of the EMTs who were tested in the study are well-prepared in ACLS, but many have great deficits in BCLS, particularly in the area of CPR. Trainees performed ACLS functions such as an intubation or a defibrillation well. The trainees consistently utilized incorrect cardiac compression and ventilation rates during CPR.

Key Words: advanced cardiac life support; basic cardiac life support; competency; emergency medical technicians; quality vocational training; "emergency-parcours"

\section{Training of Specialists-Coordinators Within the System of Disaster Medicine Service \\ S.V. Trifonov; V.A. Zhukov; I.I. Sakbno \\ All-Russian Centre for Disaster Medicine "Zaschita," Moscow, Russia}

Disaster Medicine, as a scientific discipline of graduate and postgraduate training of medical personnel, was introduced in Russia at the beginning of the 1990s. The Chairs of Disaster Medicine were established in all medical colleges and postgraduate training institutions. A Methodological Council was set up at above chairs within the framework of the Russian Federation (RF) Ministry of Public Health on the basis of the AllRussian Centre for Disaster Medicine (ARCDM), "Zaschita." The Council deals with the certification of training institutions entitled to teach specialists in Disaster Medicine services and with the pursuing the common policy in teaching of this discipline.

To develop planning of postgraduate Disaster Medicine specialists training, ARCDM "Zaschita" conducts research into estimating the demands of such specialists regarding social and demographic factors and the scope of previous training.

The head chair in the training of the service executive personnel was established in 1994 on the basis of
ARCDM “Zaschita." Thus far, 540 specialists-coordinators of Disaster Medicine services have undergone postgraduate training under the direction of the chair. The education of the specialists is accomplished at a permanent centre and on the traveling basis. The lectures on the traveling basis receive a great deal of attention, as they are the most economical ones.

The main educational forms specified by the unified curriculum of postgraduate physician (pharmacist) training in Disaster Medicine consist of: lectures, practical studies, seminars, staff training (exercises), business games, etc. The aims and tasks of postgraduate training of the service specialists and coordinators belonging to different hierarchical levels correspond to their functional and professional status.

Key Words: disaster medicine; training of the personnel

\section{The Positive Training Impact for 489 Physicians and Surgeons on Duty at the Public Hospitals of Rio de Janeiro \\ Marcos Musafir; Roberto Frota Pessoa; \\ Ronaldo Gazolla; Eduardo Kanaan \\ Rio de Janeiro, Brazil}

The Trauma Association of Rio de Janeiro and the local order of the Orthopaedic and Traumatology Association combined with the public emergency city government, provided 16 courses to 30 doctors each in hospitals in the Systematic Management of the Polytraumatized Patient, directed at the reality and necessity of the 8 million people living in that area, where the provision of emergency care is totally free.

The courses of two days each were held from September until November, 1996 at the Veterinarian Institute. They were composed of lectures, panel discussions, case presentations, practice models, accident simulations, and written tests.

The students believed that frequent training in emergencies and trauma, is very important for improving the quality of the patient care. The positive impact of the courses was related to the inclusion of the routines required to manage the polytraumatized patient, the motivation of the health care workers on duty, the tremendous economy of materials, medication, machines, and products. But, the most important effect was the re-duction of the mortality rate by $18 \%$ in Rio. All the details and statistics will be shown during the presentation.

Key Words: courses; polytrauma; quality; systematic management

\section{Disaster Management in Extreme Environments Victor S. Koscheyev, $M D, P h D$}

Division of Kinesiology, University of Minnesota, Minneapolis, Minnesota USA

The effects of severe environments, such as extreme cold or heat, are factors that must be included in response planning and in the early and continuing management of disasters. These environmental conditions have an 